\title{
Activity and space patterns of Pyrenean desman (Galemys pyrenaicus) suggest non-aggressive and non-territorial behaviour
}

Article

Accepted Version

Melero, Y., Aymerich, P., Santulli, G. and Gosàlbez, J. (2014) Activity and space patterns of Pyrenean desman (Galemys pyrenaicus) suggest non-aggressive and non-territorial behaviour. European Journal of Wildlife Research, 60 (5). pp. 707-715. ISSN 16124642 doi: https://doi.org/10.1007/s10344014-0838-8 Available at https://centaur.reading.ac.uk/83111/

It is advisable to refer to the publisher's version if you intend to cite from the work. See Guidance on citing.

To link to this article DOI: http://dx.doi.org/10.1007/s10344-014-0838-8

Publisher: Springer

All outputs in CentAUR are protected by Intellectual Property Rights law, including copyright law. Copyright and IPR is retained by the creators or other copyright holders. Terms and conditions for use of this material are defined in the End User Agreement. 


\section{CentAUR}

Central Archive at the University of Reading

Reading's research outputs online 


\section{Activity and space patterns of Pyrenean desman (Galemys pyrenaicus) suggest non-}

2 aggressive and non-territorial behaviour

3 Y. Melero ${ }^{1,2}$, P. Aymerich ${ }^{1}$, G. Santulli ${ }^{1}$, and J. Gosàlbez ${ }^{1}$

$4{ }^{1}$ Department of Animal Biology (Vertebrates), University of Barcelona, Spain

$5 \quad{ }^{2}$ School of Biological Sciences, University of Aberdeen, AB24 2TZ Aberdeen, UK

6

7 Correspondence author: Yolanda Melero

$8 \quad$ E-mail address: melero@ub.edu; telephone: +44(0)1224272789

9

Keywords Activity pattern; Galemys pyrenaicus; movement pattern; Pyrenean desman; social organization

12

\section{Abstract}

14 The Pyrenean desman is considered as a flag species of biodiversity and evolution. However, 15 its scientific knowledge is still under development and currently on debate, in special in 16 relation to the behavioural ecology and social organization. Based on the previous hypothesis

17 of individual desmans being solitary and territorial, activity and space patterns were

18 described as arranged to avoid conspecifics. However, recent new insights into the species social behaviour revealed non-interspecific avoidance. With this study we provide novel insights into their activity and space patterns and their relation to the social behaviour. A total of 30 individuals were trapped of which 18 provided informative radiotracking data to study (1) individuals activity behaviour, (2) proportion of home range utilised and movement distances, and (3) movement directionality. Activity and space use patterns were affected by daylight and seasonality but not by sex, age or number of other conspecifics sharing the home range. In contrast to the previous observations, individuals did not show a pattern of 26 directionally in their movements. Noticeably, we observed encounters between individuals 
27 without evidence of aggressive behaviour between them. Our results suggest that desmans do 28 not opposite their activity neither their spatial behaviour in order to avoid encounters with 29 conspecifics as previously suggested. These novel findings provide more evidences of a 30 social structure and organization with social interactions and non-aggressive behaviour. This 31 is of relevance for management actions and conservation purposes of this endemic mammal. 32

33

34 Authors declare no conflict of interest 
36 The Pyrenean desman (Galemys pyrenaicus; also known as Iberian desman) is a riparian

37 species considered as a flag species of biodiversity and evolution because of its relic and narrow endemic character. Together with the Russian desman (Desmana moschata) represent the last two extant species of the Desmanini lineage of Soricomorpha (Nowak 1999) a mammalian taxa of extremely high biodiversity value. However, the species has been quite unknown to the general public due to its nocturnal elusive behaviour; and to the scientific community because the difficulty of its study (due to e.g. the few approved capture authorisations or the difficulty of scat identification using non-genetic methodologies since desman and shrew scats can easily be misidentified)

The first published information on its social and ecological behaviour was thanks to the novel studies carried by (Stone 1987b; Stone 1987a; Stone 1985; Stone and Gorman 1985), Stone (1987b; 1987a; 1985) in wild watercourses, and Richard and Michaud (1975) and Richard $(1986 ; 1985)$ in captivity. Since then a few seminal studies have talked about its distribution, morphology and general biology (Aymerich and Gosàlbez 2013; Aymerich and Gosàlbez 2002; Bertrand 1993; Palomo et al. 2007; Queiroz and Almada 1993; WilliamsTripp et al. 2012) and most of them are grey literature and/or have low international repercussion. Nonetheless, in the recent years the interest on the species has increased notably by both the general public and the scientific community. Indeed, the Pyrenean desman recently became strictly protected under the Bern Convention (Appendix II) and the EU Habitats and Species Directive (Annexes II and IV). Notwithstanding, the scientific knowledge on its behaviour and ecology is still poorly developed. One of the most unknown aspects of the species biology is its behavioural ecology and the reliability of little available information is currently on debate. The species was first observed as largely territorial and solitary or organised in couples in the wild (Stone 1987a; 
60 Stone and Gorman 1985) and solitary in captivity (Richard and Viallard 1969). This

61 hypothesis was supported by observations that described the individuals as highly aggressive

62 with conspecifics independently of the sex even between couples, except for temporal mating

63 and transient individuals (Stone 1987a). Since these first studies, there has been no more

64 research on its social organization or behaviour, and these observations have been the

65 foundation for the knowledge on the species behavioural ecology. Consequently, many

66 studies were based on the aegis of desmans being aggressive with resident male and female

67 couples occupying an exclusive range in which the male's range encloses that of the female,

68 and individuals hold exclusive shelters (Richard and Valette Viallard 1969; Stone 1987b;

69 Stone 1987a; Stone 1985). Controversially, we recently observed a different social behaviour

70 with non-territoriality nor conspecific avoidance (Melero et al. 2012). More in detail, we

71 found that socio-spatial organization was community based with non-exclusive or permanent

72 territories and shared home ranges and resting sites (shelters used for more than $1 \mathrm{~h}$ ) between

73 two or more resident non-couple individuals of different and/or same sex. Our new findings

74 thus, recalled for a re-evaluation of the behavioural ecology of the species and the subsequent

75 related research and management actions.

$76 \quad$ Under the observations of Stone $(1985 ; 1987 \mathrm{a} ; \mathrm{b})$ individual behaviour was observed

77 to be arranged to avoid conspecifics. It was described as a bimodal activity rhythm with one

78 diurnal and one nocturnal activity bout during which the whole riparian territory was seen to

79 be patrolled on a $48 \mathrm{~h}$ basis if solitary and $24 \mathrm{~h}$ basis in the case of mating couples sharing the

80 territory. In this patrolling, males were more frequently found in the border areas of the river

81 sections included in their territories to protect the territory and mating couples avoiding

82 encounters between them. In addition, individuals had fixed directional up or downstream

83 movements that were organised between individuals to avoid encounters, including couples

84 except for mating encounters. However, under the novel recent observations of the species 
The study was conducted in the river Tor, located in the Eastern Pyrenees (UTM 31TCH61). We selected $2 \mathrm{~km}$ of the river Tor which presented $4 \mathrm{~m}$ of mean width, 0.1-0.4 $\mathrm{m}$ of mean

not being territorial or aggressive (Melero et al. 2012), individual activity and space use might not follow the previously postulated objective of avoidance.

In this study, we investigated the activity and space use patterns of a local population of Pyrenean desman. We hypothesised that individual activity and space use patterns were not organised to avoid conspecific encounters. To test our hypothesis we studied (1) individuals activity behaviour (active versus inactive), (2) proportion of home range utilised and movement distances during the activity bouts, and (3) directionality of individual desmans. We also state several observed spatiotemporal encounters between individuals. Our overall aim was to increase the scarce research and knowledge on the behaviour of the species. We believe that clarifying the scientific knowledge on the species behaviour is crucial for the understanding of the species biology and its conservation. This will contribute to the awareness of the species and, ultimately, to improve design of on-going and future research, management and conservation actions.

\section{Material and methods}

The study area and the methodology for trapping and radiotracking was previously described in the in Melero et al. (2012) because the data used in this study was a subset of the data used in the preceding publication consisting of individuals captured between 2002 and 2004 in the river Tor.

Study area

$$
\text { depth, and } 6.5 \% \text { of mean slope, rocky river-bed and rocky shorelines covered by dense }
$$


111 vegetation. The river Tor is a well preserved river without anthropogenic pressures. Winter

112 snowfalls and their subsequent spring thaws maintain a constant high river flow with a peak

113 in April-May but without significant seasonal differences. Mean altitude of the area ranges

114 between 1200 and $1400 \mathrm{~m}$ and precipitation falls regularly along the year within a range of

115 800-1000 mm being the highest between May and September. Temperatures in the area range

116 from an average of $20^{\circ} \mathrm{C}$ in summer to $-2{ }^{\circ} \mathrm{C}$ in winter.

117 Other aquatic and semiaquatic vertebrates sharing the habitat with the Pyrenean

118 desman are the brown trout Salmo trutta, viperine snake Natrix Maura, White-throated

119 Dipper Cinclus cinclus, the Eurasian Water Shrew Neomys fodiens, the water vole Arvicola

120 sapidus and the Eurasian otter Lutra lutra. The river provides availability of a diverse

121 invertebrate fauna such as caddisflies (Trichoptera) and mayflies (ephemeroptera) among

122 others.

123

124 Trapping and radiotracking

125

126 Two trapping sessions of 5 to 7 days each were conducted annually with 28-35 trap nights per

127 session between 2002 and 2004. The sessions were set each year in April to June (spring-

128 summer, spring hereafter) and in September-October (autumn) to cover both the expected

129 reproductive and the non-reproductive seasons (Castién 1994). Animals were live trapped at

130 night in partially submerged unbaited mesh traps designed for trapping the species and based

131 on the designs of eel traps. Traps were located inside the rivers in adequate places for

132 trapping (i.e. narrow pathways) maintaining a separation of 30-300 $\mathrm{m}$ between them and

133 checked every 3 hours during the night every day (traps were open during daylight hours).

134 After immobilization with anaesthetic (isoflurane), animals were measured, weighted, sexed,

135 aged and classified as either a new capture or a recapture. Animals were classified by sex and

136 age based on the data of Peyre (1961), González-Esteban et al. (2003) and González-Esteban 
et al. (2002) respectively. The captured animals were marked with a subcutaneous transponder (PIT; ID K162 FDX-B; AEG ID; Trovan Ltd., Madrid, Spain) and radiotransmitter (frequency 150-151, Pip model, BioTrack, Ltd., Wareham, Dorset, UK and

140 Tinyloc Ltd., Mataró, Spain). Transponders weighted approximately $0.95 \mathrm{mg}<1.7 \%$ of the

141 lightest individuals (M16 and F11, weight $=54 \mathrm{~g})$. Radiotransmitters weighted approximately

$142 \quad 2.5-3 \mathrm{~g}<5.5 \%$ of the weight of the lightest individuals and $<4.4 \%$ of the heaviest individual

$143 \quad(\mathrm{~F} 8$, weight $=70 \mathrm{~g})$. All manipulated animals were released in the capture area once fully

144 recovered. None of the captured individuals died during the procedures. Trapping was carried

145 out by three accredited biologist and one accredited veterinary, but animal manipulation was

146 carried out only by the accredited veterinary. Research permit and accreditations were

147 provided by the Scientific Ethical Committee of the Department of Environment and Housing 148 of the Catalonian Government (Spain). Our methods followed the "Guidelines for the Use of 149 Animals in Research" (Association for the Study of Animal Behaviour and Animal Behavior 150 Society 2012). All recaptured animals showed a good condition with no effects by the 151 manipulation, the transponder or the transmitter. Failed radiotransmitters of recaptured 152 individuals were removed following procedures explained above.

153 Radiotracking was done with a RX-8910HE (Televilt International AB) and three

154 multidirectional and bidirectional antennas (for long, medium and short distances) with a 155 mean precision of 0.2 and $0.1 \mathrm{~m}$ respectively. Radiolocations were recorded by homing to the 156 animals without triangulation as desman movements follow the river course. The study area 157 did not have proper coverage for GPS systems. Therefore, animal position was recorded and 158 mapped following as reference the $100 \mathrm{~m}$ signals of the road that flows parallel to the river (1 $159-10 \mathrm{~m}$ distance, mean $=7 \mathrm{~m}$ ). This and the narrow width of the river facilitated the location of 160 the individuals with the precision of the bidirectional antennas being the limiting factor $161(0.1 \mathrm{~m})$. 
164 due to recovery from manipulation. Animal location was made daily; during night each 165 individual was radiotracked every $1-2 \mathrm{~h}(\widetilde{\mathrm{x}}=1.2, \mathrm{SD}=0.3)$ when they were active and every 10-20 min when inactive to detect the re-start of the activity. During daylight

167 radiotracking was made every $30-60 \mathrm{~min}$. All individuals were tracked for $10-15 \mathrm{~min}$ after 168 located.

Activity patterns

172 Activity and inactivity behaviour was defined based on time spent outside (activity) or inside

173 (inactivity) the resting site. Diurnal time was set between dawn and dusk for each day and

174 nocturnal between dusk and dawn. Activity $(n=589)$ versus inactivity $(n=1024)$ was

175 studied using only radiolocations separated at least $1 \mathrm{~h}$ to reduce temporal autocorrelation except when individuals changed their behaviour leading to $n=559$ and 977 respectively.

177 The influence of sex, age, daylight (diurnal and nocturnal), season (spring-autumn) and 178 number of conspecifics sharing the home range were analysed by means of generalised lineal 179 mixed models (GLMM). Activity was fitted as to a binary distribution, and best model fit was 180 selected based on AIC. Factors were set as fixed effects except for individual that was set as random effect. By considering individual as random effect, we tested individual variation and avoided the problem of different number of repeated measures per individual. For conspecific sharing the territory that also had concurrently radiolocations we 184 analysed if their frequencies of activity per hour were correlated with the activity of the other 185 individual by means of a Pearson correlation. Overall, we had enough concurrently information for two pairs of individuals sharing the space: F1-F3 and M6-M15, and one pair

187 of individuals captured together F10-M11. Radiotracking did not show space overlap

188 between the pair F10-M11 but included it based on the fact that at some point the did share it. 
190 Space use patterns

191

192 Space use was evaluated based on the home range use in terms of the percentage of the home 193 range utilised during the individuals' daily activity as calculated as lineal meters of river

194 section utilised. Home range size was obtained and exposed in our previously study (Melero 195 et al. 2012). In relation to the movement patterns, we studied the distances travelled during 196 the activity periods per day and the direction of the movement (upstream and downstream) 197 using all radiolocations $(\mathrm{n}=1613)$. Distance travelled per activity bout was defined as the 198 sum of the distances from the resting site to the distal location points without counting 199 sections travelled more than once (because e.g. of forward and backward movements).

200 Percentage of home range used and direction of movement were set to binomial distributions, 201 and distances travelled to a Gaussian distribution. All three variables were tested against the 202 influence of sex, age, daylight (diurnal and nocturnal), season (spring-autumn) and number of 203 conspecifics sharing the home range by means of GLMMs and linear mixed model (LMM) 204 for distances travelled. We followed the same procedure as in the activity analyses for the 205 fixed and random effects.

All models were fit in package lme4 and based on Restricted Maximum Likelihood 207 (REML) and package lme done in R. Model selection was based on AIC criteria.

209 Results

210

211 We obtained the most completed radiotracking and trapping dataset up to date. A total of 30 212 individuals were trapped of which 18 provided enough radiotracking data to study their 213 activity and home range (ten males and eight females). Individuals were tracked for at least 2 
214 days and for a maximum of 33 days $(\breve{\mathrm{x}}=25.3, \mathrm{SD}=10.5$; Table 1$)$. The remaining

215 individuals were not radiotracked due to transmitter failure before 2 days of radiotracking.

217 Activity pattern

218

219 On average, individuals spent more time inactive than active with $36.51 \%(\mathrm{SD}=23 \%)$ of 220 active radiolocations, 9-10 h of activity per day. In general, the activity of desman was mainly nocturnal although the activity pattern differed between autumn and spring. During autumn, individuals presented two nocturnal, or exceptionally three, activity bouts with an average duration of 5 hours $(\mathrm{SD}=1.5)$ each separated by one (exceptionality 2 ) inactive

224 period of 100 minutes of average duration $(S D=57.81)$ commonly happening at $2 \mathrm{pm}$ approximately, and a single diurnal activity bout of 73.75 minutes of average $(\mathrm{SD}=45.69$; Fig. 1a). In spring, however, nocturnal activity was reduced to a single bout $(\widetilde{\mathrm{x}}=8 \mathrm{~h}, \mathrm{SD}=$ 1.6) without any inactive period but diurnal activity was longer $(\widetilde{\mathrm{x}}=102 \mathrm{~min}, \mathrm{SD}=52.51$; 228 Fig. 1b).

Best model fit included season and daylight but dismissed sex, age and number of conspecifics in the home range as factors influencing the activity pattern (in addition, in all models $p>0.1$ for dismissed factors). Both season and daylight had a significant effect on activity $(F=10.51, d f=1, p<0.0001$ and $F=2.61, d f=1, p=0.009$ respectively $)$ although

233 their interaction was not significant $(\mathrm{F}=-0.25, d f=3, p=0.79)$. Overall, individuals

234 presented higher probability of being active at spring nights, followed by autumn nights;

235 however, variability was also highest in them nocturnal spring activity (Fig. 2). Variance due to the random effect was low (7\%) indicating low individual variability.

All cases where we had enough data on conspecifics sharing the territory showed a

238 significant correlation between their frequencies of activity per hour. This correlation was 239 high in the case of F1 and F3 $\left(r^{2}=0.83, d f=22, p<0.0001\right)$, and lower in the case of M6 and 
$240 \mathrm{M} 15\left(r^{2}=0.48, d f=18, p=0.001\right)$; similar to the pair trapped together F10 and M11 $\left(r^{2}=\right.$

$2410.31, d f=21, p=0.006)($ Fig. 3).

243 Space use pattern

244

245 Home range was almost completely utilised during their total nocturnal movements in

246 autumn (average percentatge of utilisation $\widetilde{\mathrm{x}}=76.03 \%, \mathrm{SD}=24.09$ ) with a slightly

247 significant reduction in spring $(\widetilde{\mathrm{x}}=58.55 \%, \mathrm{SD}=17.10 ; F=-2.65, d f=1, p=0.01$; Fig.

248 4). During the daylight activity bouts home range was only partially utilised $(11.6 \%$ in

249 autumn and $6.2 \%$ in spring with not significant differences, $p>0.1$; Fig. 4). Best model fit

250 included season and daylight but dismissed sex, age and number of conspecifics in the home

251 range as factors influencing the movement distances (in addition, in all models $\mathrm{p}>0.1$ for

252 dismissed factors). There was no significant variability between individuals (variance due to

253 random effect $=0.9 \%$ ).

254 Distances travelled by the individuals at each activity bout were highest at night and 255 in autumn $(268.5 \pm 123.9 \mathrm{~m})$, with significant differences between seasons $(F=13.77, d f=1$, $256 p<0.0001)$ and daylight $(F=140.89, d f=1, p<0.0001$; Fig. 5

257 ) but not with other factors. As before, best model fit all other factors (in all models $\mathrm{p}>0.07$

258 for dismissed factors). Variability due to individuals was again low (13\%). During these

259 displacement movements, individuals were observed to frequently travel from the resting site 260 to the distal site of their home range and afterwards either rest in the same or different resting 261 site or travel to the opposite distal point before resting. In relation to the direction of the 262 movement, best model fit included all factors but there were no differences in the direction of 263 the movement (up or downstream) for any of the models (all $p$-values $>0.4$ ). Diurnal 264 movements were always one way movement from the resting site and return to the same or, 
exceptionally, a different resting site. In all cases, individuals' movement was straight

266 forward, without forward and backward movements.

Spatio-temporal encounters

269

270 Several individuals were found to share the home range for 1- to 24- days (Table 1) and, of

271 them the pairs F1 and F3, and M6 and M15 were both found together in the same location in 272 eight occasions during six and three days of radiotracking respectively. In all the cases did 273 not seem to alter their behaviour for conspecific avoidance. Encounters last from 10 seconds 274 to up $10 \mathrm{~min}$, but no longer than 5 minutes when all individuals were actively moving.

\section{Discussion}

278 This study provides evidence of the non-avoidance behaviour among individuals of Pyrenean

279 desman. The individual activity and space use patterns of the studied population were not 280 organised to avoid conspecifics. Indeed, we could directly observe encounters between 281 individuals of different or same sex.

As previously described by Stone (1987b; 1987a), individuals presented a bimodal activity pattern in spring consisting of primary nocturnal activity bout $(\widetilde{\mathrm{x}}=8 \mathrm{~h})$ of average

284 and a short activity bout during daylight $(\widetilde{\mathrm{x}}=102 \mathrm{~min})$. However, we observed a shift from

285 this bimodal activity rhythm to a trimodal and exceptionally tetramodal in autumn. At this 286 time individuals included 1 or 2 nocturnal resting bouts $(\widetilde{\mathrm{x}}=100 \mathrm{~min})$ and reduced their 287 diurnal activity to a single and shorter bout $(\widetilde{\mathrm{x}}=73.75 \mathrm{~min})$ without resting time. This activity rhythm was never observed before, probably to the fact that Stone's previous studies

289 were always done in spring time. This shift in their rhythm is probably related to the 290 individuals' ability to adapt their behaviour to the duration of the night at different seasons. 
Indeed, the only factors affecting their activity pattern were seasonality and daylight. It is

292 possible that there is also relation between the duration of the diurnal and nocturnal activity 293 and the biomass intake and/or the individuals' energetic requirements. The probability of 294 activity during spring nights increased because there is not resting period and, thus, the 295 probability of finding an individual active was higher, but the duration of the total nocturnal 296 activity is shorter in spring when nights are also shorter than in the studied months of autumn.

297 However, the duration of the diurnal activity bout increases in this spring, which might be 298 related to a necessity of feeding to maintain its energetic requirements. Unfortunately, our 299 data did not provide information to test this hypothesis.

Coinciding with Stone's previous studies, individual variation in the activity pattern was very low (7\% variation due to individual effect) and independent of their sex, age and, 302 more interesting of the number of conspecifics sharing the home range with them. These results support the previous hypothesis of a common activity pattern between individuals. In fact, for those cases sharing the home range where we had enough data, the activity of the individuals was significant correlated; information that, together with the model, supports the idea of a similar activity pattern between individuals.

In concordance with the observed activity pattern, seasonality and daylight were also the only factors influencing the range use and movement pattern of the studied population. In both cases, individual desmans utilised higher percentage of their home ranges and travelled longer distances at night and in autumn (76.03\% versus $58.55 \%$ in spring nights). During the 311 daylight activity bouts home range was only partial utilised (11.6\% in autumn and $6.2 \%$ in 312 spring with not significant differences, $p>0.1$; Fig. 4). In addition, individual variation was again low (only $0.9 \%$ in the case of the home range use and $13 \%$ for travelled distances)

314 which indicated a common pattern with independence of the sex, age or number of 315 conspecifics sharing the home range. This findings, contradict the previous view that 316 described their spatial behaviour based on sexual differences and conspecifics avoidance 
317 (Stone 1987a; Stone 1985). Under the hypothesis of individuals being solitary and aggressive,

318 the spatial behaviour of males and females was suggested to differ in order to maintain a

319 mutual avoidance. This was based on the observations that the direction of the movements

320 (upstream or downstream) seemed to differ between sexes which was explained as a pattern

321 to avoid encounters with conspecifics occurring even in paired individuals (Stone 1987a;

322 Stone 1985). In addition, males were observed to travel further distances than female while

323 females mainly stayed in the neighbourhood of the resting site. Controversially, our results

324 support a common spatial pattern for both females and males and a lack of mutual avoidance.

325 Indeed, we observed no differences in the direction of the movement (up or downstream)

326 between sexes, ages, daylight (diurnal and nocturnal), season (spring-autumn) or in relation

327 to the number of conspecifics sharing the home range.

328 Our results indicate a general common behavioural pattern between individual

329 desmans with a lack of mutual avoidance. This is supported by our previous findings were

330 individuals on individuals concurrently sharing resting sites with independence of their sex or

331 age (Melero et al. 2012). Activity and space patterns were previously explained based on the

332 hypothesis of conspecific avoidance. However, our results suggest that individuals of

333 Pyrenean desman do not organise their activity neither opposite their spatial behaviour in

334 order to avoid encounters with conspecifics as previously suggested (Stone 1987b; Stone

335 1987a). Indeed, we could directly observe encounters with individuals without evidence of

336 aggressive behaviour between them. The reasons for the differences between our studies and

337 those by Stone are yet unknown. Differences in prey availability could be the first suggestion;

338 however, there is not available data to test this hypothesis and both rivers seem to present

339 similar resources and conditions. Notwithstanding, our current and previous findings are

340 consistent with the behaviour of the most similar species, the Russian desman (Onufrenya

341 and Onufrenya 1993). This species has similar ecological to the desman but it is considered a 
342 semi nomadic and non-territorial (Nowak 1999; Onufrenya and Onufrenya 1993) with social

343 interactions between conspecifics.

344 Overall, based on our current observation and our previous study on the shelter use

345 behaviour, we recall for a new understanding on the species behaviour based on a social

346 organization hypothesis where individuals are non-aggressive neither territorial.

348 Management and conservation implications

350 Our findings are of significant relevance for management and conservation purposes of the 351 species. The species distribution and status is currently being monitored by several national 352 and international projects in Spain, France and Portugal (e.g. LIFE+ Desmania) mostly by 353 means of indirect signs surveys consisting on annual scat surveys to map its distribution and 354 potential expansion/contraction. In the past, the species distribution has also been mapped 355 using other indirect signs that included not only scats but also interview to local residents. This type of information is, however, less reliable than the current methodology based on scat surveys. None of these methodologies allow identifying individuals and thus, estimating the density. Genetic monitoring using the collected scats will allow identifying individual. Until 359 this is achieved, density estimations could be wrongly estimated if the surveys are based on the previous hypothesis. First, under the hypothesis of desmans being solitary and territorial, density has been calculated assuming a maximum of two (mating couple) individuals per mean home range (e.g. two individuals per 200-500m). However, based on our results there

363 could be more than two individuals in the same home range length and thus, density would be

364 underestimated. Estimation of population density based on presence absence data should be 365 thus updated and used with criticism since until now they were done on the basis of individuals being in couples and maintaining fixed territories (e.g. Nores et al. 1998). 
367 In addition, as observed in our previous study Melero et al. (2012) home ranges might not be

368 fixed over the seasons and/or years. Thus, density could also be overestimated based when

369 working with the hypothesis of fixed territories. Furthermore, this hypothesis of fixed

370 territories can overestimate the species distribution, and connectivity between populations.

371 This is due because, as with the density, distribution and connectivity are estimated based on

372 presence absence data (direct captures or presence - absence of signs consisting mainly of

373 scat surveys) assuming desmans do not change their territories. However, we have provided

374 evidences of individuals with passing areas and temporal displaced home ranges.

375 Hence, we recommend population monitoring include shared territories and social

376 interactions that allow more than two desmans per home range. In addition, based on our

377 current and previous results (Melero et al. 2012) we also recommend to include the existence

378 of passing areas and temporal home ranges (individuals changing the size and location of

379 their home ranges) and to prioritize those river sections that are permanently occupied versus 380 those temporally occupied.

382 Acknowledgments

383 The authors are grateful to the accredited veterinary Francisco Mañas for his collaboration 384 during the trapping campaigns. We also thank the Official Consultant from the Ministerio de 385 Medio Ambiente. The project was funded by the Departament d'Agricultura, Ramaderia, 386 Pesca, Alimentació i Medi Natural and (programme no. BOS 2003-08823-CO3-01), the 387 Ministerio de Ciencia and the Generalitat de Catalunya (programme no. 2001SGR0088). The 388 research permit numbers provided by the Catalonian Government were SF/159, SF/073 and 389 SF/178 for 2002, 2003 and 2004 respectively. We thank the two anonymous reviewers for 390 their helpful comments. 
Association for the Study of Animal Behaviour, Animal Behavior Society (2012) Guidelines for the treatment of animals in behavioural research and teaching. Anim Behav 83:301309. doi: 10.1016/j.anbehav.2011.10.031

Aymerich P, Gosàlbez J (2014) El desmán ibérico (Galemys pyrenaicus) en los Pirineos meridionales. Gestión y Conservación los mamíferos semiacuáticos en el suroeste Europa. Munibe. In press.

Aymerich P, Gosàlbez J (2002) Factors de distribució de Galemys pyrenaicus (Insectivora, Talpidae) a Catalunya. Orsis 17:21-35.

Bertrand A (1993) Stratégies alimentaires du Desman des Pyréneés Galemys pyrenaicus dans un cours d'eau des Pyrénées françaises. Proc. Meet. Pyrenean Desman. Lisbon, pp 4152

Castién E (1994) Estudio bioecológico de la comunidad de micromamíferos (Insectivora y

González-Esteban J, Villate I, Castién E, et al. (2002) Age determination of Galemys pyrenaicus. Acta Theriol (Warsz) 47:107-112.

González-Esteban J, Villate I, Castién E (2003) Sexual identification of Galemys pyrenaicus. Acta Theriol (Warsz) 48:571-573. doi: 10.1007/BF03192502

Igea J, Aymerich P, Fernández-González A, et al. (2013) Phylogeography and postglacial expansion of the endangered semi-aquatic mammal Galemys pyrenaicus. BMC Evol Biol 13:115. doi: 10.1186/1471-2148-13-115

Melero Y, Aymerich P, Luque-Larena JJ, Gosàlbez J (2012) New insights into social and space use behaviour of the endangered Pyrenean desman (Galemys pyrenaicus). Eur J Wildl Res 58:185-193. doi: 10.1007/s10344-011-0561-7

Nores C, Ojeda F, Ruano A, et al. (1998) Estimating the population density of Galemys pyrenaicus in four Spanish rivers. J Zool London 246:454-457.

Nowak RM (1999) Walker's mammals of the world. 793.

Onufrenya AS, Onufrenya M V (1993) Desman in Oka State Reserve (Russia). Proc Meet Pyrenean Desman 81-83.

Palomo LJ, Gisbert J, Blanco JC (2007) Atlas y libro rojo de los Mamíferos de España. SECEM-Ministerio de Medio Ambiente, Madrid, pp 92-98

Peyre A (1961) Recherches sur l'intersexualité spécifique chez Galemys pyrenaicus. short captivity. Proc. Meet. Pyrenean Desman. Lisbon, pp 33-39

427 Richard B (1986) Le desman des Pyrénées, un mammifère inconnu à découvrir. Monaco: Le 
429 Richard B (1985) Étude préliminaire sur les rythmes d'activité du desman (Galemys pyrenaicus) en captivité. Mammalia 49:317-323.

431

432

433

434

435

436

437

438

439

440

441

442

443

444

445

446

447

448

449

450

Richard B, Michaud C (1975) Le carrefour trachéen dans l'adaptation du Desman des Pyrénées (Galemys pyrenaicus) à la vie dulçaquicole. Mammalia 39:467-477.

Richard B, Viallard VA (1969) Le Desman des Pyrénées (Galemys pyrenaicus). Notes sur sa biologie. Terre Vie 23:225-245.

Stone RD (1987a) The social organization of the Pyrenean desman (Galemys pyrenaicus) as revealed by radiotelemetry. J Zool 212:117-129. doi: 10.1111/j.14697998.1987.tb03680.x

Stone RD (1985) Home range movements of the Pyrenean desman (Galemys pyrenaicus) (Insectivora: Talpidae). Zeitschrift fuer Angew Zool 72:25-37.

Stone RD (1987b) The activity patterns of the Pyrenean desman ( Galemys pyrenaicus ) (Insectivora: Talpidae), as determined under natural conditions. J Zool 213:95-106. doi: 10.1111/j.1469-7998.1987.tb03680.x

Stone RD, Gorman ML (1985) Social organization of the European mole (Talpa europaea) and the Pyrenean desman (Galemys pyrenaicus). Mamm Rev 15:35-42. doi: 10.1111/j.1365-2907.1985.tb00385.x

Williams-Tripp M, D’Amico FJN, Pagé C, et al. (2012) Modeling Rare Species Distribution at the Edge: The Case for the Vulnerable Endemic Pyrenean Desman in France. Sci World J 2012:1-6. doi: 10.1100/2012/612965 
451 Table 1 Radiotracked individuals, number of tracked days and of radiolocations, season,

452 percentage of active radiolocations, size of the home range (meters of river section),total

453 number of conspecifics in their home range for 2- to 24- days and season Adapted from

454 Melero el at. (2012).

\begin{tabular}{|c|c|c|c|c|c|c|c|c|}
\hline Indiv. & Sex & $\begin{array}{l}\text { Age at } \\
\text { capture }\end{array}$ & $\begin{array}{l}\text { No. of } \\
\text { tracked days }\end{array}$ & $\begin{array}{l}\text { No. } \\
\text { radiolocations }\end{array}$ & Season & $\begin{array}{l}\% \text { active } \\
\text { radiolocations }\end{array}$ & $\begin{array}{l}\text { Home } \\
\text { range } \\
\text { (m) }\end{array}$ & $\begin{array}{l}\text { Conspecifics } \\
\text { in home } \\
\text { range }\end{array}$ \\
\hline $\mathrm{F} 1$ & Female & Adult & 25 & 111 & Autumn & 42.34 & 570 & F3 \\
\hline F2 & Female & Adult & 21 & 126 & Autumn & 37.30 & 520 & - \\
\hline F3 & Female & Adult & 24 & 130 & Autumn & 41.54 & 430 & $\mathrm{~F} 1$ \\
\hline F4 & Female & Adult & 9 & 37 & Autumn & 35.13 & 530 & M2* \\
\hline F6 & Female & Adult & 8 & 64 & Autumn & 57.81 & 450 & M5 \\
\hline F9 & Female & Juvenile & 3 & 11 & Autumn & 45.45 & - & - \\
\hline F10 & Female & Juvenile & 17 & 136 & Spring & 42.65 & 350 & - \\
\hline F11 & Female & Adult & 19 & 117 & Autumn & 19.66 & 660 & - \\
\hline \multirow[t]{2}{*}{ M1 } & Male & Adult & 34 & 206 & Spring & 34.95 & $530-$ & - \\
\hline & & & & & & & $2300^{\dagger}$ & \\
\hline M4 & Male & Adult & 20 & 112 & Spring & 40.18 & 620 & F5* \\
\hline M5 & Male & Adult & 2 & 6 & Autumn & 0 & - & F6 \\
\hline \multirow[t]{3}{*}{ M6 } & Male & Adult & 33 & 232 & Spring & 31.03 & $550-$ & $\mathrm{F} 7 *, \mathrm{~F} 8, \mathrm{M}^{*}$ \\
\hline & & & & & $\&$ & & $1350^{\dagger}$ & M15 \\
\hline & & & & & Autumn & & & \\
\hline \multirow[t]{2}{*}{ M7 } & Male & Adult & 4 & 20 & Spring & 30 & 670 & M10*, M12*, \\
\hline & & & & & & & & M8 \\
\hline \multirow[t]{2}{*}{ M8 } & Male & Juvenile & 16 & 134 & Autumn & 35.07 & 650 & M10*, M12*, \\
\hline & & & & & & & & M7 \\
\hline
\end{tabular}




\begin{tabular}{lllllllll}
\hline M9 & Male & Juvenile & 3 & 4 & Spring & 0 & - & - \\
M11 & Male & Juvenile & 7 & 48 & Spring & 41.67 & 320 & - \\
M15 & Male & Adult & 7 & 37 & Autumn & 37.83 & 450 & M6 \\
M16 & Male & Adult & 8 & 75 & Autumn & 37.33 & 510 & - \\
\hline
\end{tabular}

$455 *$ marked individuals that did not provide enough information for the analyses.

456 Outliers due to exceptional one day long movements. Outliers were not taken into account in 457 the analyses.

458 
459 Figure 1 Percentage and standard error of activity per hour of the studied population of

460 Pyrenean desman in (a) autumn $(n=994)$ and $(b)$ spring $(n=669)$ seasons. Data was

461 gathered by means of radiolocation.

462

463 Figure 2 Estimated probability of being active for the studied population of Pyrenean

464 accordingly to daylight (diurnal and nocturnal) and season (autumn and spring). Values are 465 given as mean and their standard error calculated from the GLMM.

466

467 Figure 3 Estimated activity correlation between pairs of the studied population of Pyrenean 468 desman F3-F1, M15-M6 and F10-M11. Values are given as between percentage of active 469 radiolocations per hour (\%). Dotted lines stand for the estimated correlation.

470

471 Figure 4 Estimated percentage of home range utilised of the studied population of Pyrenean

472 desman accordingly to daylight (diurnal and nocturnal) and season (autumn and spring).

473 Values are given as mean and their standard error calculated from the GLMM.

474

475 Figure 5 Estimated total distance travelled during the activity bouts of the studied population

476 of Pyrenean desman accordingly to daylight (diurnal and nocturnal) and season (autumn and

477 spring). Values are given as mean and their standard error calculated from the GLMM.

478 